\title{
Icariin promotes early and late stages of fracture healing in rats
}

\author{
İkariin sıçanlarda kırık iyileşmesinin erken ve geç evrelerini destekler
}

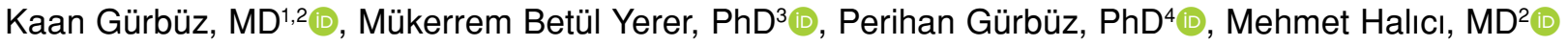 \\ ${ }^{1}$ Department of Orthopedics and Traumatology, Kayseri City Hospital, Kayseri, Turkey \\ ${ }^{2}$ Department of Orthopedics and Traumatology, Faculty of Medicine, Erciyes University, Kayseri, Turkey \\ ${ }^{3}$ Department of Pharmacology, Faculty of Pharmacy, Erciyes University, Kayseri, Turkey \\ ${ }^{4}$ Department of Pharmacognosy, Faculty of Pharmacy, Erciyes University, Kayseri, Turkey
}

\begin{abstract}
Objectives: This study aims to evaluate the effects of locally applied icariin on bone fracture healing in femur fractured rat model.

Materials and methods: The study included 64 male Sprague-Dawley rats (mean age 6 months; weighing, 280-490 g) in eight main study groups. Fracture healing process and level were evaluated with radiography, histopathology and dual energy X-ray absorptiometry to investigate the effects of local administration of icariin at varying doses, which is an exogenous osteo-inductive substance. Activities of superoxide dismutase (SOD) and glutathione peroxidase (GPx) were measured in the peripheral blood in addition to glutathione (GSH) and myeloperoxidase (MPO) levels to investigate the effects of icariin on the oxidant-antioxidant systems.
\end{abstract}

Results: Radiological bone mineral density measurements and histopathological findings revealed that icariin improved all these parameters in the two healing periods tested. Superoxide dismutase activity decreased in association with local icariin application to the fractured side whereas GPx and GSH increased and MPO remained unchanged. Icariin increased the GPx and GSH levels which are responsible from scavenging hydroxyl radical and hydrogen peroxide.

Conclusion: Locally administered icariin to the fracture accelerated bone healing by reducing the oxidative stress.

Keywords: Epimedium, flavonoid, fracture healing, icariin, radical scavenging activity.

Many plant-derived natural products have been used in traditional medicine for the treatment of various diseases. Herba Epimedii is a traditional
ÖZ

Amaç: Bu çalışmada femur kırıklı sıçan modelinde lokal olarak uygulanan ikariinin kemik kırığı iyileşmesi üzerine etkileri değerlendirildi.

Gereç ve yöntemler: Çalışmaya sekiz ana çalışma grubunda 64 erkek Sprague-Dawley sıçan (ort. yaş 6 ay; ağırlık, 280-490 g) dahil edildi. Bir ekzojen osteo-indüktif madde olan ikariinin lokal olarak değişen dozlarda uygulanmasının kırık üzerine etkilerini araştırmak için kırık iyileşme süreci ve düzeyi radyografi, histopatoloji ve çift enerjili X-ışını absorbsiyometrisi ile değerlendirildi. İkariinin oksidanantioksidan sistemler üzerindeki etkilerini araştırmak için glutatyon (GSH) ve miyeloperoksidaz (MPO) düzeylerine ek olarak periferal kanda süperoksit dismutaz (SOD) ve glutatyon peroksidaz (GPx) aktiviteleri ölçüldü.

Bulgular: Radyolojik kemik mineral yoğunluğu ölçümleri ve histopatolojik bulgular, ikariinin test edilen iki iyileşme döneminde tüm bu parametreleri geliştirdiğini ortaya koydu. Süperoksit dismutaz aktivitesi kırıklı tarafa lokal ikariin uygulaması ile birlikte azalırken, GPx ve GSH arttı ve MPO değişmedi. Ikariin, hidroksil radikali ve hidrojen peroksiti süpürmekten sorumlu olan GPx ve GSH düzeylerini artırdı.

Sonuç: Lokal olarak kırık üzerine uygulanan ikariin oksidatif stresi azaltarak kemik iyileşmesini hızlandırdı.

Anahtar sözcükler: Epimedium, flavonoid, kemik iyileşmesi, ikariin, radikal süpürücü aktivite.

herbal medicine that has been reported as an effective enhancer of bone healing, ${ }^{[1]}$ and it has been stated that its extracts can reduce the occurrence of

Received: May 08, 2019 Accepted: July 01, 2019 Published online: October 24, 2019

Correspondence: Kaan Gürbüz, MD. Kayseri Șehir Hastanesi, Ortopedi ve Travmatoloji Kliniği, 38039 Kocasinan, Kayseri, Turkey. Tel: +90532-4086503 e-mail: drkagangurbuz@gmail.com 
osteoporosis not only in experimental studies but also in clinical studies. ${ }^{[2]}$ It is known to increase the overall mineral content and therefore to promote bone formation and to increase lumbar bone mineral density (BMD). ${ }^{[3]}$ In addition, the flavonoids of Herba Epimedii have been shown to concurrently improve osteogenic differentiation and inhibit the osteoclastic differentiation of human bone marrow-derived cells. ${ }^{[4]}$ It is suggested that Epimedium-derived flavonoids including icariin have an anabolic effect on osteoporotic bone by concomitantly promoting the osteogenic differentiation of bone marrow stromal cells ${ }^{[5,6]}$ while suppressing adipogenic differentiation. ${ }^{[7]}$

Fracture healing and bone repair which may result in unfavorable extension involve a combination of a series of complicated processes. ${ }^{[8]}$ Oxidative stress, which is a cause of excessive production of free radicals, contributes to many different pathological conditions, including ischemia/perfusion, vasculogenesis and so on $\cdot^{[9]}$ In order to stabilize the oxidation-reduction equilibration of free radicals in living organisms, first the removal of the radicals is achieved through enzymatic, i.e., first natural defense superoxide dismutase (SOD), myeloperoxidase (MPO), and glutathione $(\mathrm{GSH})$, and nonenzymatic reactions. ${ }^{[10]}$

At the promotion stage of fracture healing, a putative multiple-strategy approach involving local and cell-based systemic therapies that manipulate the morphogenetic processes is used to promote healing. ${ }^{[8]}$ In this study, we aimed to evaluate the effects of locally applied icariin on bone fracture healing in femur fractured rat model.

\section{MATERIALS AND METHODS}

This study was conducted at Erciyes University, Experimental Research and Application Centre between 01 September 2013 and 30 October 2013. Sixty-four male Sprague Dawley rats (mean age 6 months; weighing, 280-490 g) were used in the study that were kept in individual cages at a constant temperature of $23 \pm 2^{\circ} \mathrm{C}$ with a $14 / 10$ hours' light-dark cycle and fed standard pellet food and tap water. All procedures were performed in the Experimental Animals Breeding and Research Center of the Medical Faculty of Erciyes University, Kayseri, Turkey. Animal care was carried out with the prior approval of the Erciyes University Animal Experimental Ethics Committee on 10 April 2013 with approval number 13/63 and was in full compliance with Turkish Law 6343/2, Veterinary Medicine Deontology Regulation 6.7.26, and the Helsinki Declaration of Animal Rights.

The right femurs of all rats were fractured under intra peritoneal $3 \mathrm{mg} / \mathrm{kg}$ xylazine hydrochloride and ketamine hydrochloride general anesthesia. A Ruijin ${ }^{\mathrm{TM}}$ mini micro bone oscillating sagittal saw (Wuhu Ruijin Medical Instrument and Device Co., Ltd, Anhui, China) was used to create standard fractures as similar to each other as possible. Retrograde fixation was carried out using $1.5-\mathrm{mm}$ Kirschner wires. The rats were randomly allocated to eight groups each consisting of eight rats: two control groups (control$3 \mathrm{w}$ and control-6w) and six study groups (icariin$3 w 2.5 \mathrm{mg}$, icariin-3w10 mg, icariin-3w25 mg, icariin$6 \mathrm{w} 2.5 \mathrm{mg}$, icariin-6w10 mg, and icariin-6w25 mg). The control groups did not receive any additional treatment after surgical intervention. In the study groups, icariin was applied to the fracture locally once just after the fracture was created with the bone oscillating saw at dosages of $2.5,10$, or $25 \mathrm{mg}$. Icariin$3 w 2.5 \mathrm{mg}$, icariin-3w10 mg, icariin-3w $25 \mathrm{mg}$, and control-3w groups were sacrificed three weeks and the remaining groups were sacrificed six weeks after the surgical intervention. Before the animals were sacrificed, anteroposterior and lateral radiographies of the femur were obtained, whole body BMD was measured, and $3 \mathrm{~mL}$ of blood was withdrawn for antioxidant analysis. After the rats were sacrificed, their entire right femurs were obtained and kept in $10 \%$ formaldehyde solution.

A previously described five-point scoring system modified by Warden et al. ${ }^{[1]]}$ was used to evaluate fracture healing: 0 points: no evidence of healing; 1 point: callus formation evident but fracture gap not bridged; 2 points: callus formation evident with bridging of the fracture gap but fracture line evident; 3 points: callus formation evident with bridging of the fracture gap with only faint fracture line; 4 points: fracture union. The radiological evaluation of each femur was performed in a double-blind manner by an orthopedist and a radiologist with no connection to the study. The mean of these fracture healing scores was used for analysis.

Dual-energy X-ray absorptiometry with a Hologic QDR 4500 ELITE Acclaim Series (Hologic, Massachusetts, USA) was used to measure the BMD of the femurs. High resolution measurements of area, bone mineral content, and BMD data were obtained from a region of interest approximately 1.6 (length) $\times 1.28$ (width) $\mathrm{cm}$ over the region of osteotomy in the left limb as well as the osteotomy-equivalent site in the right intact limb.

A 10-point scale was used for the histological evaluation of fracture healing::[12] 1 point: only fibrous; 2 points: predominantly fibrous tissue; 3 points: equal amounts of fibrous and cartilage tissue; 4 points: predominantly cartilage tissue with little fibrous 
TABLE I

Bone mineral density values for all groups

\begin{tabular}{lcc}
\hline Groups $(\mathrm{n}=8)$ & $\begin{array}{c}\text { Mean } \pm \mathrm{SD} \\
\left(\mathrm{g} / \mathrm{cm}^{2}\right)\end{array}$ & $\begin{array}{c}p \text { for overall } \\
\text { difference }\end{array}$ \\
\hline Control group sacrificed at third week & $0.145 \pm 0.002$ & $0.152 \pm 0.000$ \\
Control group sacrificed at sixth week & $0.155 \pm 0.008$ & $<0.001$ \\
Locally $2.5 \mathrm{mg}$ icariin applied group sacrificed at third week & $0.166 \pm 0.006$ & $0.172 \pm 0.002$ \\
Locally $10 \mathrm{mg}$ icariin applied group sacrificed at third week & $0.170 \pm 0.004$ & $0.188 \pm 0.004$ \\
Locally $25 \mathrm{mg}$ icariin applied group sacrificed at third week & $0.202 \pm 0.006$ & \\
Locally $2.5 \mathrm{mg}$ icariin applied group sacrificed at sixth week & & \\
Locally $10 \mathrm{mg}$ icariin applied group sacrificed at sixth week & & \\
Locally $25 \mathrm{mg}$ icariin applied group sacrificed at sixth week & & \\
\hline
\end{tabular}

SD: Standard deviation.

tissue; 5 points: only cartilage tissue; 6 points: predominantly cartilage tissue with little immature bone tissue; 7 points: equal amounts of cartilage and immature bone tissue; 8 points: predominantly immature bone tissue with little cartilage tissue; 9 points: healing with immature bone tissue; 10 points: healing with mature bone tissue. The histopathological evaluation of each femur was conducted in a doubleblind manner by a pathologist with no connection to the study.

Superoxide dismutase, GSH, GPx, and MPO levels were measured in the plasma. Blood samples for biochemical tests were taken from the right femoral vein of the rats. To obtain standard values of each biochemical parameter, eight rats in which fractures had been created in their femurs and physiological saline was applied locally were sacrificed at three weeks and eight more at six weeks. After separation of plasma, the samples were stored at $-20^{\circ} \mathrm{C}$ until analysis. Spectrophotometric analyses were performed with a Biotec Synergy Multifunctional Microplate Reader using SOD (Biovision's SOD assay, Biovision Inc., Milpitas, CA, USA), total GSH (Cayman's GSH assay, Cayman Chemical Company, Ann Arbor, MI, USA), GPx (Biovision's GPx assay, Biovision Inc., Milpitas, CA, USA), and MPO (Cayman's MPO assay, Cayman Chemical Company, Ann Arbor, MI, USA) commercial kits according to the kit procedure.

\section{Statistical analysis}

The Shapiro-Wilk test and graphical methods were used to test the normality of the data. Intergroup comparisons of normally distributed continuous variables were performed using one-way analysis of variance. The Tukey honestly significant difference test or Dunnett's T3 test was used for pairwise comparisons depending on the homogeneity of variances. For the intergroup comparisons of variables without normal distribution, the Kruskal-Wallis test was used, and the Bonferroni corrected Mann-

TABLE II

Radiological scores of all groups

\begin{tabular}{|c|c|c|c|c|c|c|c|c|c|}
\hline \multirow[b]{2}{*}{ Groups $(n=8)$} & \multicolumn{2}{|c|}{1 Point } & \multicolumn{2}{|c|}{2 Points } & \multicolumn{2}{|c|}{3 Points } & \multicolumn{2}{|c|}{4 points } & \multirow[b]{2}{*}{$p$} \\
\hline & $\mathrm{n}$ & $\%$ & $\mathrm{n}$ & $\%$ & $\mathrm{n}$ & $\%$ & $\mathrm{n}$ & $\%$ & \\
\hline Control group sacrificed at third week & 0 & 0 & 4 & 50 & 4 & 50 & 0 & 0 & \multirow{8}{*}{0.0019} \\
\hline Control group sacrificed at sixth week & 0 & 0 & 1 & 12.5 & 5 & 62.5 & 2 & 25 & \\
\hline Locally $2.5 \mathrm{mg}$ icariin applied group sacrificed at third week & 0 & 0 & 4 & 50 & 2 & 25 & 2 & 25 & \\
\hline Locally $10 \mathrm{mg}$ icariin applied group sacrificed at third week & 0 & 0 & 3 & 37.5 & 3 & 37.5 & 2 & 25 & \\
\hline Locally $25 \mathrm{mg}$ icariin applied group sacrificed at third week & 0 & 0 & 3 & 37.5 & 2 & 25 & 3 & 37.5 & \\
\hline Locally $2.5 \mathrm{mg}$ icariin applied group sacrificed at sixth week & 0 & 0 & 2 & 25 & 4 & 50 & 2 & 25 & \\
\hline Locally $10 \mathrm{mg}$ icariin applied group sacrificed at sixth week & 0 & 0 & 3 & 37.5 & 1 & 12.5 & 4 & 50 & \\
\hline Locally $25 \mathrm{mg}$ icariin applied group sacrificed at sixth week & 0 & 0 & 1 & 12.5 & 3 & 37.5 & 4 & 50 & \\
\hline
\end{tabular}


Whitney U test was used for pairwise comparisons. $P$ value $<0.05$ was considered statistically significant.

\section{RESULTS}

Bone mineral density was higher among rats in which icariin had been locally applied compared with their control groups at both three and six weeks (Table I). There was no significant difference between the three and six week groups. The highest BMD was in the icariin- $6 \mathrm{w} 25 \mathrm{mg}$ group $(\mathrm{p}<0.05)$.

Similarly, radiological evaluation scores (Table II) were higher in the groups in which icariin had been locally applied compared with the controls at both three and six weeks $(p<0.05)$. The icariin-3w25 mg group had the highest radiological score at three weeks among both the control and study groups (Figure 1). On the other hand, the icariin-6w10 $\mathrm{mg}$ group had the highest score overall $(\mathrm{p}<0.001)$ (Figure I).

Histopathological assessment scores were better at six weeks in the groups in which 10 and $25 \mathrm{mg}$ of icariin had been locally applied, whereas the difference was not statistically significant at three weeks (Figure 2a, b). Additionally, the BMD and histopathological assessment scores showed a dosedependent improvement between the two time points among the rats given icariin.

The plasma levels of the antioxidants SOD, GSH, and GPx are shown in Figures 3, 4, and 5, respectively. Plasma SOD activity was decreased approximately $50 \%$ among the groups in which icariin had been locally applied compared with the controls at both three and six weeks. The lowest SOD activity $(42 \%)$ was determined in the icariin-6w25 $\mathrm{mg}$ group $(\mathrm{p}<0.05)$. Glutathione values were highest in the icariin-3w10 mg and icariin-3w25 mg groups compared to the controls at both three and six weeks and compared to the icariin-6w2.5 mg, icariin-6w10 $\mathrm{mg}$, and icariin-6w $25 \mathrm{mg}$ groups $(\mathrm{p}<0.05)$. According to these results, icariin increased the activity of GPx enzyme. The highest amount of GPx activity was at six weeks $(2.5 \mathrm{mg})$ while the lowest was at three weeks $(10 \mathrm{mg})$ in the study group. When these results were evaluated with the amount of GSH in the three week study group, which had the lowest GSH amount, the GPX had the lowest enzyme activity; on the other hand, in the six week study group, which had the lowest GSH, GPx had the highest enzyme activity. At three weeks, while the amount of GSH was high, GPx enzyme activity was low; the high radical scavenging effect of icariin was indicated at this week. At six weeks, icariin
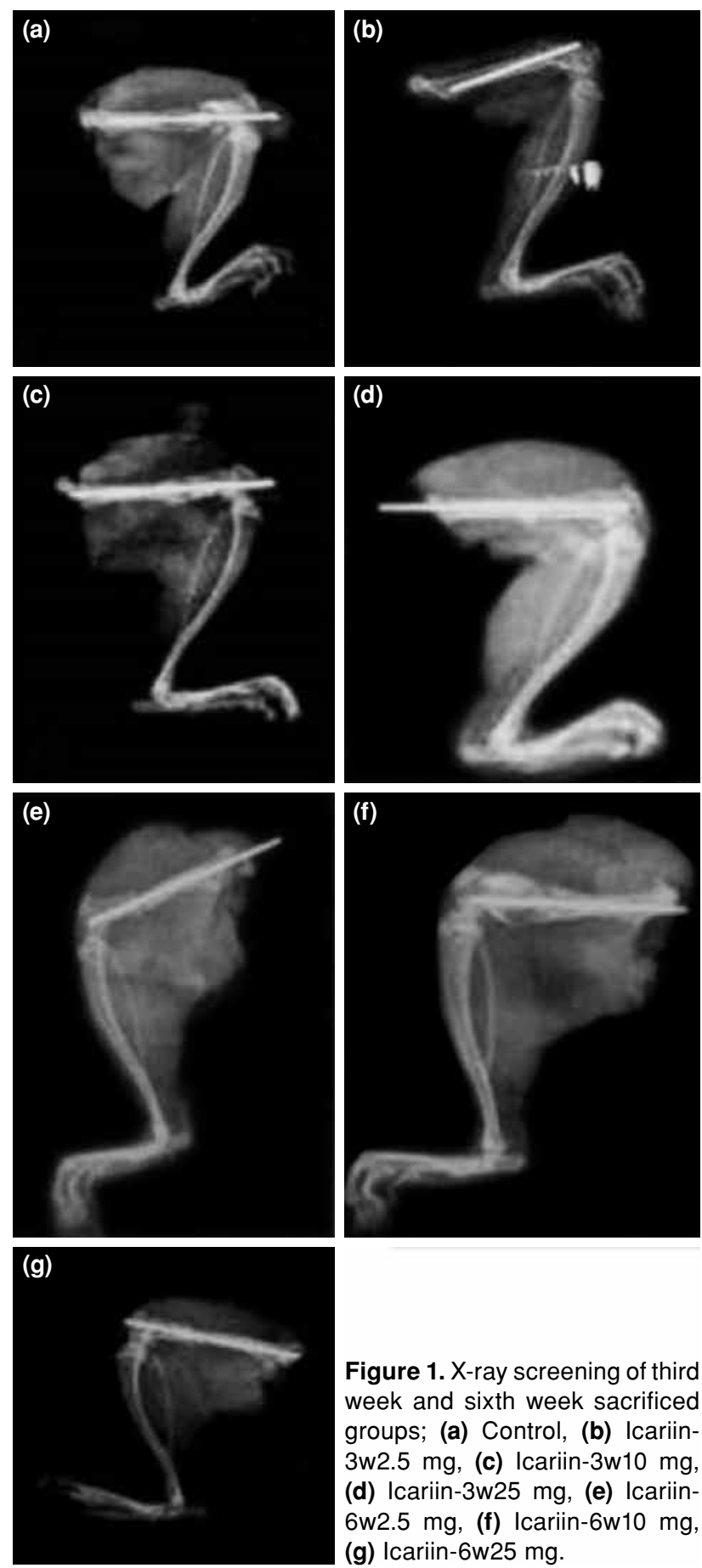

Figure 1. X-ray screening of third week and sixth week sacrificed groups; (a) Control, (b) Icariin$3 w 2.5 \mathrm{mg}$, (c) Icariin-3w10 mg, (d) Icariin-3w25 mg, (e) Icariin$6 \mathrm{w} 2.5 \mathrm{mg}$, (f) Icariin-6w10 mg, (g) Icariin-6w25 mg.

may cause an increase in the amount of GPx by increasing the expression of GPx enzyme. There was no significant difference in MPO activity within the groups $(p>0.05)$.

\section{DISCUSSION}

The present study revealed the favorable effects of icariin in bone fracture, a condition associated 
(a)

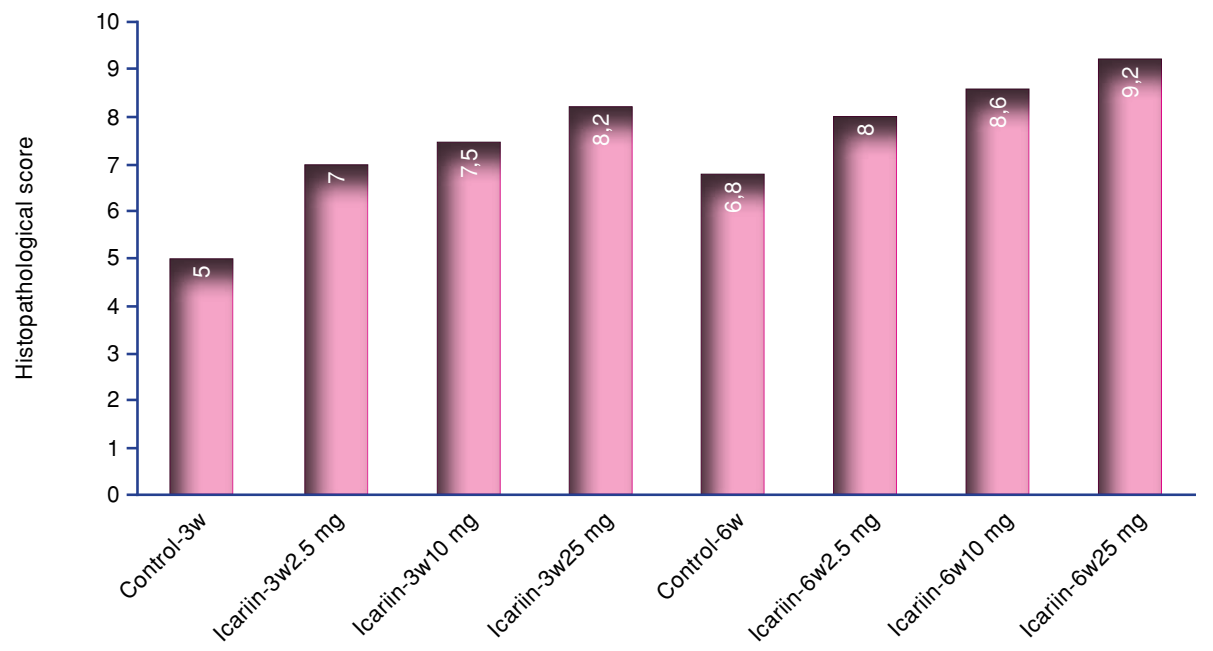

(b)
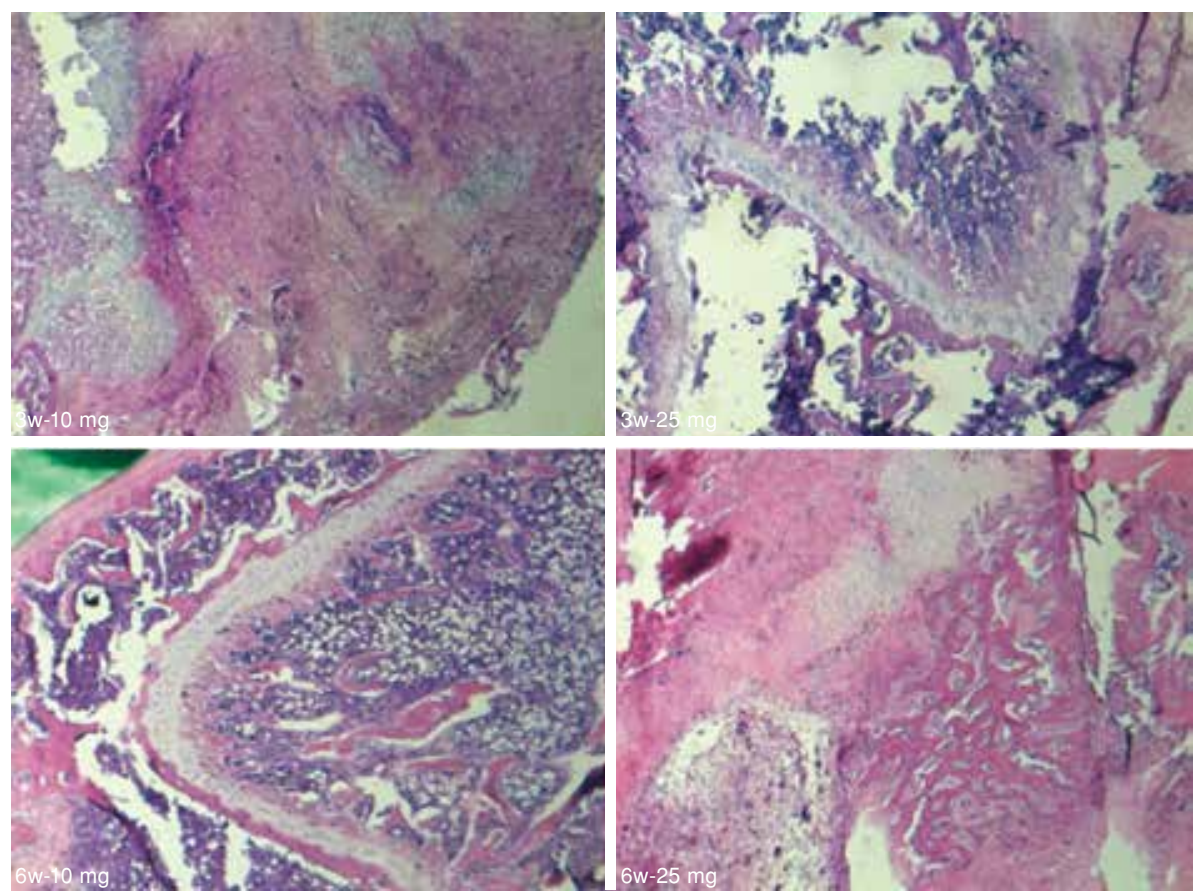

Figure 2. (a) Histopathological assessment scores of all groups. (b) Histopathological microscopy of samples $(\mathrm{H}-\mathrm{E}, \times 100)$.

with oxidative stress, in terms of both better healing and alterations in endogenous antioxidant levels. To determine the effects of icariin on the fractured side, the BMD of the callus tissue and histopathologic views of the fracture healing stages are also investigated.

Icariin had time- and dose-dependent positive effects BMD which was shown by the present study within rat's metabolism experimentally. This effect was supported and proved by Cao et al. ${ }^{[13]}$ that icariin inhibits osteoporosis in vitro, potentially owing to its role in increasing bone morphogenetic protein-2 (BMP-2) expression, and that icariin promotes bone formation via the BMP-2/Smad4 signal transduction pathway in the human fetal osteoblastic 1.19 cell line. ${ }^{[14]}$ In addition, the osteoblastic mechanism of icariin was demonstrated on MC3T3-E1 (osteoblast precursor cell line) cells and it was proved that icariin could facilitate MC3T3-E1 cells ingrowth and regulate osteoblastic differentiation. ${ }^{[15]}$ Also, recent studies demonstrated that icariin stimulates 


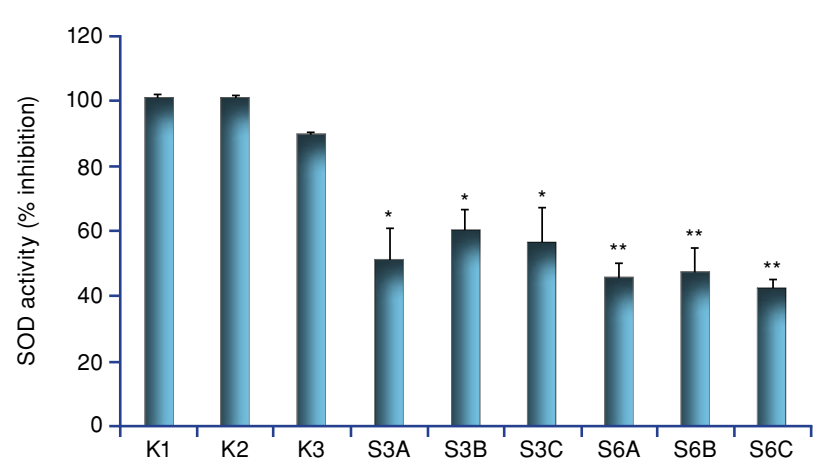

Figure 3. Superoxide dismutase activities of groups with standard deviation: K1: Pre-fracture value; K2: Post-fracture, third week control group; K3: Post-fracture, sixth week control group; S3A: Post-fracture, third week study group (2.5 mg icariin); S3B: Post-fracture, third week study group (10 mg icariin); S3C: Post-fracture, third week study group (25 mg icariin); S6A: Post-fracture, sixth week study group (2.5 mg icariin); S6B: Post-fracture, sixth week study group (10 mg icariin); S6C: Post-fracture, sixth week study group (25 mg icariin).

* Statistically significant compared to K2 ( $\leq \leq 0.005) ;{ }^{*}$ Statistically significant compared to K3 $(p \leq 0.005)$.

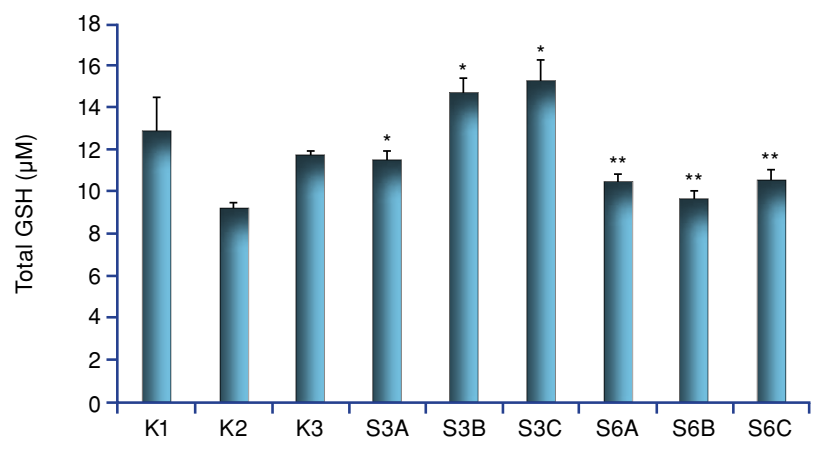

Figure 4. Glutathione amounts of groups with standard deviation: K1: Pre-fracture value; K2: Post-fracture, third week control group; K3: Post-fracture, sixth week control group; S3A: Post-fracture, third week study group (2.5 mg icariin); S3B: Post-fracture, third week study group (10 mg icariin); S3C: Post-fracture, third week study group (25 mg icariin); S6A: Post-fracture, sixth week study group (2.5 mg icariin); S6B: Post-fracture, sixth week study group (10 mg icariin); S6C: Post-fracture, sixth week study group ( $25 \mathrm{mg}$ icariin).

* Statistically significant compared to K2 ( $\leq \leq 0.005) ;{ }^{* *}$ Statistically significant compared to $K 3(p \leq 0.005)$.

osteoblast precursor cells (MC3T3) derived from mouse calvaria proliferation.

The radiological evaluation scores were higher in the groups in which icariin had been locally administered. Those findings support the facilitation of bone formation by icariin via several mechanisms such as signal transduction effect, some bone formation related protein expression effect. ${ }^{[13,14]}$

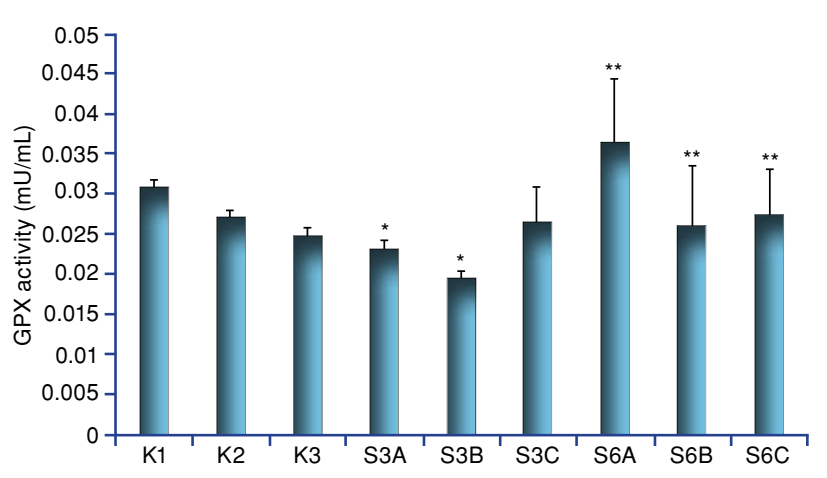

Figure 5. Glutathione peroxidase activities of groups with standard deviation: K1: Pre-fracture value; K2: Post-fracture, third week control group; K3: Post-fracture, sixth week control group; S3A: Post-fracture, third week study group (2.5 mg icariin); S3B: Post-fracture, third week study group (10 mg icariin); S3C: Post-fracture, third week study group (25 mg icariin); S6A: Post-fracture, sixth week study group (2.5 mg icariin); S6B: Post-fracture, sixth week study group (10 mg icariin); S6C: Post-fracture, sixth week study group (25 mg icariin).

* Statistically significant compared to K2 $(p \leq 0.005) .{ }^{* *}$ Statistically significant compared to K3 $(p \leq 0.005)$.

Histopathological assessment scores were better as the time passed after the occurrence of fracture. In the present study, sixth week scores were higher in all groups regarding the controls. This should be related to the effect of icariin on osteoblasts and osteoclasts. This situation might be clarified by icariin's simulative effects on osteoblasts, inhibition of osteoclast differentiation ${ }^{[5,6]}$ and suppression of osteoclastogenesis. ${ }^{[7]}$

Recent meta-analysis about in vivo studies of icariin indicates that icariin has a high osteo-inductive potential as a biomaterial for use in bone tissue engineering. According to this meta-analysis, icariin has several effects on the musculoskeletal system including anti-osteoporosis, osteogenesis, antiosteoclastogenesis, chondrogenesis, angiogenesis, and anti-inflammatory activities. ${ }^{[16]}$

The effects of icariin on the oxidant-antioxidant system were evaluated in this study biochemically by measuring the activities of SOD and GPx as well as GSH and MPO levels in the peripheral blood. SOD activity decreased in association with local icariin application to the fractured side, whereas GPx and GSH increased and MPO remained unchanged. This alteration may be explained by the reduced need for endogenous antioxidant SOD scavenging superoxide dismutase $\left(\mathrm{O}^{\circ}\right)$ radical. Furthermore, icariin increased the GPx and GSH levels, which are responsible for scavenging hydroxyl radical $\left(\mathrm{OH}^{*}\right)$ and hydrogen peroxide $\left(\mathrm{H}_{2} \mathrm{O}_{2}\right)$. This effect might be due to the radicals formed in the environment 
during the activation period of the enzymes. The activation of first defense antioxidant mechanisms; GPx and GSH due to the formation of $\mathrm{OH}^{*}$ radical and $\mathrm{H}_{2} \mathrm{O}_{2}$ might reduce the amount of $\mathrm{O}^{*}$ radical. The reduced $\mathrm{O}^{*}$ radical causes less need for $\mathrm{SOD}$ activity; therefore, in the present study, SOD should be decreased. However, this should be further investigated molecularly to identify its mechanisms of action on these enzymes.

Furthermore, icariin was also shown to inhibit apoptosis and preserve viability by reducing the production of reactive oxygen species and malonyldialdehyde and increasing SOD activity. ${ }^{[17]}$ Another study related to the in vitro antioxidant effects of icariin showed that significantly decreased amounts of 1, 1diphenyl-2-picryl hydrazyl, O2ं, and $\mathrm{OH}^{*}$ radicals were detected when the cell culture medium was treated with icariin. ${ }^{[18]}$

This study has some limitations such as biomechanical and molecular evaluation of the study and control groups unioned fractures. Another limitation is application type and dosage. The clinical effects of icariin; local or sistemic, optimum dosage for aplications should be investigated in detailed.

In conclusion, locally administered icariin to the fracture facilitates bone healing via improving antioxidant responses within the fracture site. Further bimolecular studies are required to highlight the underlying mechanism of these effects. In addition, the effects of icariin in clinical settings are warranted.

\section{Acknowledgement}

The authors are indebted to the Research Foundation of Erciyes University (Project ID: TTU-2013-4551) for its financial support in this work and thanks are also due to Professor Dr. Hulya Akgun, MD, (Department of Pathology, Erciyes University, Faculty of Medicine) for histopathological examination of the fracture healing. The authors would also like to thank native English editor, Dr. Russell Fraser, for editing the article.

\section{Declaration of conflicting interests}

The authors declared no conflicts of interest with respect to the authorship and/or publication of this article.

\section{Funding}

The authors are indebted to the Research Foundation of Erciyes University (Project ID: TTU-2013-4551) for its financial support in this work.

\section{REFERENCES}

1. Qin L, Zhang G, Hung WY, Shi Y, Leung K, Yeung HY, et al. Phytoestrogen-rich herb formula "XLGB" prevents OVXinduced deterioration of musculoskeletal tissues at the hip in old rats. J Bone Miner Metab 2005;23:55-61.

2. An S, Li T, Li E, Effect of kidney-tonifying herbs on ovary function and bone mass in postmenopausal women. Chin J
Osteoporosis 2000;6:55-9.

3. Zhang G, Qin L, Shi Y. Epimedium-derived phytoestrogen flavonoids exert beneficial effect on preventing bone loss in late postmenopausal women: a 24-month randomized, double-blind and placebo-controlled trial. J Bone Miner Res 2007;22:1072-9.

4. Hsieh TP, Sheu SY, Sun JS, Chen MH, Liu MH. Icariin isolated from Epimedium pubescens regulates osteoblasts anabolism through BMP-2, SMAD4, and Cbfa1 expression. Phytomedicine 2010;17:414-23.

5. Fang H, Zhou L, Shen L, Zhou H, Fang Y, Fan H. Effects of icariin on the proliferation and differentiation of MC3T3-E1. Int J Clin Exp Med 2017;10:14876-82.

6. Cao H, Zhang Y, Qian W, Guo XP, Sun C, Zhang $\mathrm{L}$, et al. Effect of icariin on fracture healing in an ovariectomized rat model of osteoporosis. Exp Ther Med 2017;13:2399-404.

7. Peng S, Zhang G, He Y, Wang X, Leung P, Leung K, et al. Epimedium-derived flavonoids promote osteoblastogenesis and suppress adipogenesis in bone marrow stromal cells while exerting an anabolic effect on osteoporotic bone. Bone 2009;45:534-44.

8. Sezgin EA, Atik OŞ. Are orthobiologics the next chapter in clinical orthopedics? A literature review. Eklem Hastalik Cerrahisi 2018;29:110-6.

9. Birben E, Sahiner UM, Sackesen C, Erzurum S, Kalayci O. Oxidative stress and antioxidant defense. World Allergy Organ J 2012;5:9-19.

10. Fang $Y Z$, Yang S, Wu G. Free radicals, antioxidants, and nutrition. Nutrition 2002;18:872-9.

11. Warden SJ, Komatsu DE, Rydberg J, Bond JL, Hassett SM. Recombinant human parathyroid hormone (PTH 1-34) and low-intensity pulsed ultrasound have contrasting additive effects during fracture healing. Bone 2009;44:485-94.

12. Huo MH, Troiano NW, Pelker RR, Gundberg CM, Friedlaender GE. The influence of ibuprofen on fracture repair: biomechanical, biochemical, histologic, and histomorphometric parameters in rats. J Orthop Res 1991;9:383-90.

13. Cao H, Ke Y, Zhang Y, Zhang CJ, Qian W, Zhang GL. Icariin stimulates MC3T3-E1 cell proliferation and differentiation through up-regulation of bone morphogenetic protein-2. Int J Mol Med 2012;29:435-9.

14. Liang W, Lin M, Li X, Li C, Gao B, Gan H, et al. Icariin promotes bone formation via the BMP-2/Smad4 signal transduction pathway in the hFOB 1.19 human osteoblastic cell line. Int J Mol Med 2012;30:889-95.

15. Lai $Y$, Cao H, Wang X, Chen S, Zhang M, Wang N, et al. Porous composite scaffold incorporating osteogenic phytomolecule icariin for promoting skeletal regeneration in challenging osteonecrotic bone in rabbits. Biomaterials 2018;153:1-13.

16. Wang Z, Wang D, Yang D, Zhen W, Zhang J, Peng S. The effect of icariin on bone metabolism and its potential clinical application. Osteoporos Int 2018;29:535-44.

17. Ma HP, Ma XN, Ge BF, Zhen P, Zhou J, Gao YH, et al. Icariin attenuates hypoxia-induced oxidative stress and apoptosis in osteoblasts and preserves their osteogenic differentiation potential in vitro. Cell Prolif 2014;47:527-39.

18. Bao Y, Yang J-X, Sun R-G. Antioxidant effects of icariin and icariside II in vitro. Journal of Jilin University Medicine Edition 2012;38:423-8. 